\title{
Relative Abundance and Distribution of Mariana Swiftlets (Aves: Apodidae) in the Northern Mariana Islands ${ }^{1}$
}

\author{
Fustine B. Cruz, ${ }^{2,3}$ Shelly R. Kremer,,${ }^{2,4}$ Gayle Martin, ${ }^{2}$ Laura L. Williams, ${ }^{2}$ \\ and Vicente A. Camacho ${ }^{2}$
}

\begin{abstract}
The endangered Mariana Swiftlet, Aerodramus bartschi (Mearns, 1909), occurs in its native habitat on only three islands worldwide-Guam, Saipan, and Aguiguan. It is locally extinct on the islands of Rota and Tinian, and numbers have declined on Guam. On Saipan and Aguiguan, the bird remains common. We present previously unpublished data from reports lodged with the Commonwealth of the Northern Mariana Islands Division of Fish and Wildlife combined with an analysis of arrival count data from surveys conducted regularly on Saipan (1985-2005) and opportunistically on Aguiguan (19852002). Direct counts of swiftlets arriving at nesting caves did not permit islandwide population estimates but provided an index useful for assessing relative abundance. On Aguiguan, swiftlets occurred in only a few of the available caves; the population was small, more densely concentrated than on the other islands, and relatively stable. On Saipan, swiftlet numbers declined for the first part of the monitoring period (1985-1992), then increased significantly (1998-2005), and now stand at their highest level (>5,000 birds) since 1985. Large betweenyear fluctuations, high variation in colony attendance patterns, and occasional abandonment and recolonization of some caves were evident during the 20-yr monitoring period. Of the potential constraints to the population, pesticide use, typhoons and supertyphoons, habitat alteration by feral animals, human disturbance in the nesting caves, and predation remain areas of concern. Conservation measures may have lessened some disturbance events and nest damage by cockroaches, while other measures, such as translocation, may improve the species' chances of persistence.
\end{abstract}

The endangered Mariana Swiftlet, Aerodramus bartschi (Mearns, 1909), one of 22

\footnotetext{
${ }^{1}$ The monitoring project was supported by yearly grants from the U.S. Fish and Wildlife Service's Federal Aid to Wildlife Restoration Projects in the Commonwealth of the Northern Mariana Islands. Manuscript accepted 30 July 2007.

${ }^{2}$ Division of Fish and Wildlife, Department of Lands and Natural Resources, P.O. Box 10007, Saipan, MP 96950.

${ }^{3}$ Current address: 5 Osgood Avenue, New Britain, Connecticut 06053.

${ }^{4}$ Corresponding author. Current address: U.S. Fish and Wildlife Service, Pacific Islands Office, Box 50088, 300 Ala Moana Boulevard, Honolulu, Hawai'i 96850 (e-mail: Shelly_Kremer@fws. gov).
}

Pacific Science (2008), vol. 62, no. 2:233-246

(C) 2008 by University of Hawaici Press

All rights reserved species of Aerodramus swiftlets distributed widely on islands throughout the Indian and Pacific Oceans, was originally endemic to all five of the southern islands of the Mariana archipelago. Numbers have declined on the U.S. territory of Guam to three roosts supporting approximately 250-900 birds (Pratt et al. 1987, U.S. Fish and Wildlife Service 1991, Wiles et al. 2003). The Mariana Swiftlet may be locally extinct on the islands of Rota and Tinian (Engbring et al. 1986, U.S. Fish and Wildlife Service 1991) in the Commonwealth of the Northern Mariana Islands (CNMI). Outside their native range, a small, successful breeding colony became established on $\mathrm{O}^{\prime}$ ahu in the Hawaiian Islands after Mariana Swiftlets were brought from Guam and released intentionally in 1962 and 1965 (Wiles and Woodside 1999). It is not known if Mariana Swiftlets have formed other colonies in Hawai' $i$. 
In this paper we focus on the species in the CNMI, where it is currently restricted to two islands: Saipan (latitude $15^{\circ} 12^{\prime} \mathrm{N}$, longitude $145^{\circ} 45^{\prime} \mathrm{E}$ ), and Aguiguan (latitude $14^{\circ} 51^{\prime}$ $\mathrm{N}$, longitude $145^{\circ} 34^{\prime} \mathrm{E}$ ). A small number of colonies have been found on Aguiguan (Wiles and Worthington 2002), and on Saipan it is considered locally common (Pratt et al. 1987). On the island of Rota, the swiftlet was once abundant, as evidenced by prehistoric bone and guano deposits (Steadman 1999), old nests, and reports of senior residents (C. Rice, unpubl. data). Caves that supported colonies include Alaguan, Takta, Tonga, and Telang; apparently many hundreds of swiftlets used the latter because guano was deposited to a depth of $2 \mathrm{~m}$ in some areas (C. Rice, J. Reichel, and P. Glass, unpubl. data). Pratt et al. (1979) last recorded swiftlets on Rota in 1976, and the species has not been observed there since (Engbring et al. 1986, U.S. Fish and Wildlife Service 1991). On the island of Tinian, there is also evidence of the bird's prehistoric presence (Steadman 1999); however, a recent detailed mapping of 88 caves revealed no evidence of their presence (Stafford 2003). The few birds observed on the island in the 1940s (Marshall 1949) and 1970s (Pratt et al. 1979) may have been infrequent visitors from Saipan or Aguiguan (J. Reichel and P. Glass, unpubl. data) because many subsequent surveys on Tinian (e.g., C. Rice, J. Reichel, P. Glass, R. Craig, J.B.C., unpubl. data) have failed to detect the species. There are currently no known swiftlet breeding colonies on either Rota or Tinian, and the species is considered extirpated from both islands (Engbring et al. 1986, U.S. Fish and Wildlife Service 1991).

Mariana Swiftlets roost and nest colonially almost exclusively in natural limestone caves (Pratt et al. 1987). Most birds in a colony leave their cave at dawn to forage for insects over ridge crests, forests, and open grassy areas (U.S. Fish and Wildlife Service 1991). The entire colony returns at sunset, funneling through cave entrances to roost before nightfall. Swiftlets can echolocate, an unusual ability for birds, which allows them to enter and navigate within the darker regions of the caves they occupy (U.S. Fish and Wildlife Service 1991). A cave interior suitable for swiftlet roosting and nesting must offer crevices or pockets high on the walls or ceiling for securing nests. Nesting occurs yearround on Saipan, with peak activity between May and September (C. Rice, unpubl. data). For a more complete description of the bird's taxonomy, morphology, and natural history refer to Baker (1951), Pratt et al. (1979), Jenkins (1983), and Dickinson (2003).

The Mariana Swiftlet is listed as endangered throughout its range by the U.S. Fish and Wildlife Service (1984) and the World Conservation Union (Birdlife International 2000). It is protected also by local regulation in the CNMI as threatened and endangered (Commonwealth of the Northern Mariana Islands 2000). In 1991, the federal recovery plan for the species listed threats to its persistence as disturbance of nesting and roosting caves (including human occupation during World War II, guano mining, vandalism, visits by hunters, hikers, World War II memorabilia collectors, and feral animals), pesticide use, effects of deforestation and habitat alteration on insect prey populations, disease, cyclonic storms, and predation by the Brown Treesnake (Boiga irregularis) (U.S. Fish and Wildlife Service 1991).

Native forests on both Saipan and Aguiguan were cleared extensively for sugarcane production before World War II, reducing the birds' foraging habitat. During World War II, people used caves as bomb shelters, refuge from invading forces, and military fortifications on both Aguiguan and Saipan. Use of caves as domiciles and hospitals, and the clearing of hostile occupants using explosives and other munitions likely had deleterious effects on the swiftlet population at that time. Since World War II, the nature of disturbance has consisted mainly of guano mining, research, recreational visits, and wandering feral animals. On uninhabited Aguiguan, most visits to caves are made by hunters and fishermen from Tinian and by feral animals seeking shelter. On Saipan, caves have been used recently by spelunkers, ancestor worshipers, and as tourist destinations.

Several attributes of the Mariana Swiftlet, including its restricted distribution, small population size, and dependence on highly localized cave habitats may have increased its 
TABLE 1

Summary of Historic Data on Presence of Mariana Swiftlets in the CNMI 1945-1985

\begin{tabular}{lllllr}
\hline \hline Island & \multicolumn{1}{c}{1945} & \multicolumn{1}{c}{$1976^{a}$} & $1977^{b}$ & \multicolumn{1}{c}{$1979^{c}$} & $1^{c}$ \\
\hline Tinian & Flock $^{e}$ & A few & 0 & 0 & 0 \\
Rota & Large group $^{f}$ & Fair numbers & 0 & 0 & 0 \\
Saipan & Abundant & Common & Frequent & Small numbers & 9,120 \\
Aguiguan & - & - & - & - & 1,022 \\
\hline
\end{tabular}

Note: A dash indicates that the island was not visited.

${ }^{a}$ Pratt et al. (1979).

${ }^{b}$ Ralph and Sakai (1979).

${ }^{c}$ Jenkins and Aguon (1981).

${ }^{d}$ Engbring et al. (1986).

e Marshall (1949).

$f$ Baker (1951).

vulnerability to the deleterious effects of extensive habitat alteration and predation (i.e., Pauley 1994, Simberloff 1995). However, there is a paucity of information on which to base management actions addressing these effects (U.S. Fish and Wildlife Service 1991). Most data on the swiftlet's population status remain unpublished, although biologists have monitored a portion of the population in the CNMI for the last $20 \mathrm{yr}$. To better conserve the species we gathered historic data on the Mariana Swiftlet from previously unpublished reports and summarized the results of population monitoring in the CNMI from 1985 through 2005. The objectives of this paper are to (1) present a summary of the data on historic and current swiftlet distribution, (2) document recent abundance estimates, (3) discuss the impacts of conservation projects on the swiftlet population, and (4) review the continuing conservation needs of the species.

\section{MATERIALS AND METHODS}

\section{Site Description}

Saipan $\left(122.9 \mathrm{~km}^{2}\right)$ is the second largest island in the Mariana archipelago after Guam and is located approximately $10 \mathrm{~km}$ north of Tinian $\left(101.8 \mathrm{~km}^{2}\right)$ and $120 \mathrm{~km}$ north of Rota $\left(95.7 \mathrm{~km}^{2}\right)$. Small and uninhabited Aguiguan $\left(7.2 \mathrm{~km}^{2}\right)$, is approximately $9 \mathrm{~km}$ off the southwestern coast of Tinian. The Marianas climate is tropical, with little seasonal variation in temperature. During the "dry season," from about December through June, the northeast trade winds are strongest and rainfall is limited. A wet season lasts from approximately July to November, when the trade winds subside and heavy rains, tropical storms, and typhoons are prevalent (Young 1989). Storms primarily occur during the second half of the year and often have devastating effects on forested habitat.

\section{Population Surveys}

Early estimates of swiftlet numbers made by visiting biologists were entirely qualitative (Table 1). Quantitative census data became available when forest bird surveys were conducted islandwide in 1982 (Engbring et al. 1986). Using variable circular plot methodology, Engbring et al. (1986) estimated CNMI swiftlet population size as 1,022 on Aguiguan and 9,120 on Saipan. However, the transectbased variable circular plot method might not be an appropriate survey tool for the swiftlet, a highly mobile species that tends to concentrate near cave entrances (U.S. Fish and Wildlife Service 1991). CNMI biologists have used arrival counts, a more accurate method for surveying this species (U.S. Fish and Wildlife Service 1991), since 1985. The two survey methods are not comparable, and so we have not used the 1982 surveys for baseline comparisons.

On Aguiguan, we performed arrival counts at nine of the 91 caves that have been explored since 1985: Guano, Pillar, Landing, New, Black Noddy, Cliff, Stairway, Elvin's, and Dungkulo (Wiles and Worthington 2002; 


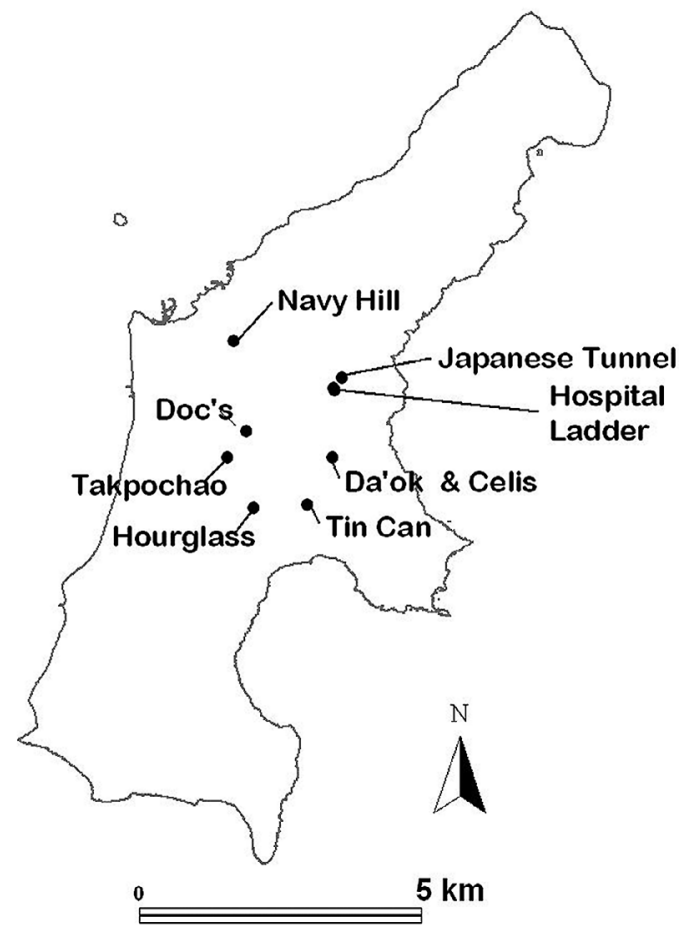

Figure 1. Map of Mariana Swiftlet colony locations on Saipan.

J. Esselstyn, unpubl. data). We conducted surveys seven times between 1985 and 2002, but the number of caves sampled was not standardized over the study period.

Swiftlet arrival counts began on Saipan in 1984 with the discovery of a single colony nesting in Celis cave (Figure 1). By 1985, another five caves with colonies (Hourglass, Navy Hill, Takpochao, Tin Can, and Do'ak) had been identified (J. Reichel and P. Glass, unpubl. data). Regular monitoring began with monthly counts conducted at Tin Can, Takpochao, Hourglass, and Navy Hill caves from 1987 to 1988. Additional swiftlet colonies were discovered in 1995 (Hospital Cave and Japanese Tunnel Cave), 1998 (Ladder Cave), and 1999 (Doc's Cave) and subsequently included in the monitoring program. No new colonies have been added to the program since 1999 (for a total of 10 colonies), with 70 surveys completed since 1985 .

Arrival count protocols were developed in 1985-1986 and standardized early in the monitoring program. On both Saipan and Aguiguan, counts started at 1700 hours and ended by 1900 hours as the birds were returning to roost for the night. Because swiftlets are sensitive to disturbances near their nesting caves, we conducted counts from outside the cave entrance, making initial estimates of the number of swiftlets inside based on amount of activity and level of vocalizations. Subsequent numbers of birds arriving or departing were then added or subtracted (original number plus number of swiftlets entering minus number of swiftlets departing) and subtotals recorded at 10 -min intervals to minimize counting errors. As light levels decreased, we often counted swiftlets by the clicking sound they use for ecolocating inside the cave. Once birds were no longer seen or heard we reported a cumulative total for the colony.

Trained observers conducted counts under clear and calm weather conditions usually within a 4- to 7-day period. A short survey period helped reduce the likelihood of miscounting birds that might be moving between roosting caves. One observer (V.A.C.) participated in surveys from 1989 to 2005, which helped to reduce observer bias. Monitoring frequency on Saipan was standardized in 1990 with counts conducted twice a year in April and October. On Aguiguan, counts were conducted opportunistically using the same methodology as on Saipan.

\section{Statistical Analyses}

On Saipan, monitoring was conducted each year between 1985 and 2005, but only $17 \mathrm{yr}$ of data were complete enough to be included in the analysis; we eliminated from consideration counts from 1993 to 1996 . We calculated the mean number of birds per cave, averaging survey results for the months of April and October to reduce the effects of missing data. A direct count index that helped assess relative abundance for the island was generated by summing the annual means across all caves. Where necessary, we used data from single surveys rather than the mean $\left(n_{1 \text { survey }}=4 \mathrm{yr}, n_{2 \text { surveys }}=13 \mathrm{yr}\right)$. In one case where counts for neither April nor October were available, we used data obtained 
during the months closest to those months in the year. Because the proportion of birds being monitored on Saipan remains unknown at this time, estimates of the size of the population were not made.

We also calculated the mean number of swiftlets in each colony over all years to help assess variation in colony attendance; means are followed by one standard deviation $( \pm S D)$, except where noted. Arrival counts were tested for reliability in 1987-1988 using multiple observers per cave (J. Reichel and P. Glass, unpubl. data) and were analyzed in 1992 (C. Rice, unpubl. data) using regression models to determine count variability and seasonal patterns.

To assess trends in swiftlet numbers we used data from only four colonies on Saipan monitored consistently since 1985 (Takpochao, Navy Hill, Tin Can, and Hourglass Caves). We averaged monthly survey results over a single year whenever possible for each of the four caves $\left(n_{\text {surveys }}\right.$ ranged from 1 to 12 per year) treating the data from 1985 to 1992 separately from those of 1998 to 2005 . We analyzed the data using both time series and multiple regression methods in Statistica (StatSoft 2003) but did not compare the early monitoring period with the later period due to differences in sample size. Trend lines were fit to the data using Microsoft Excel 2002. A trend analysis was not completed for Aguiguan due to inconsistent survey periods; instead, counts at three caves that had been sampled consistently over the study period were examined graphically.

\section{RESULTS}

On Saipan, approximately $84 \%$ of the monitored swiftlet population was sheltered in five caves: Doc's, Takpochao, Navy Hill, Tin Can, and Hourglass. Mean counts ranged from $17( \pm 17.7)$ to $938( \pm 343.6)$ birds, with

TABLE 2

Direct Count Index (DCI) of Population Size Resulting from Arrival Counts of Mariana Swiftlets from 1985 to 2005 on Saipan*

\begin{tabular}{|c|c|c|c|c|c|c|c|c|c|c|c|}
\hline Date & $\mathrm{Da}^{6} \mathrm{ok}$ & Celis & Ladder & Hospital & Doc's & $\begin{array}{c}\text { Japanese } \\
\text { Tunnel }\end{array}$ & Takpochao & $\begin{array}{l}\text { Navy } \\
\text { Hill }\end{array}$ & $\begin{array}{l}\text { Tin } \\
\text { Can }\end{array}$ & Hourglass & $\mathrm{DCI}^{a, b}$ \\
\hline $1985^{c}$ & & & & & & & 882.5 & 160 & 525 & 625 & $2,192.5$ \\
\hline $1986^{c}$ & 10 & & & & & & 560 & 297 & 785 & 477 & 2,129 \\
\hline 1987 & 10 & & & & & & 486.5 & 195 & 514 & 378.5 & 1,524 \\
\hline 1988 & & & & & & & 386.5 & 190 & 441 & 293.5 & 1,311 \\
\hline 1989 & 7.5 & 115 & & & & & 382 & 222.5 & 319 & 208.5 & $1,254.5$ \\
\hline 1990 & & 44 & & & & & 304 & 213 & 316.5 & 162 & $1,039.5$ \\
\hline $1991^{c, d}$ & & & & & & & 309 & 317 & 357 & 176 & 1,159 \\
\hline 1992 & 4 & 53 & & & & & 281.5 & 267 & 365.5 & 180.5 & $1,151.5$ \\
\hline $1997^{c}$ & & & & 173 & & 90 & & 488 & 270 & 117 & 1,138 \\
\hline 1998 & 19 & 11 & 22.5 & 181 & & 123.5 & 190 & 602 & 608 & 235 & 1,992 \\
\hline 1999 & 14 & 8.5 & 97.5 & 180.5 & 489.5 & 90 & 335.5 & 934.5 & 754 & 276.5 & $3,180.5$ \\
\hline 2000 & 8.5 & 10.5 & 153 & 279.5 & $1,180.5$ & 58.5 & 421.5 & 945.5 & 719.5 & 202.5 & $3,979.5$ \\
\hline 2001 & 17.5 & 14.5 & 178 & 254 & $1,053.5$ & 54 & 384.5 & 491.5 & 952 & 220 & $3,619.5$ \\
\hline 2002 & 36.5 & 4 & 209.5 & 148 & 765 & 35 & 264.5 & 299 & 597.5 & 130 & 2,489 \\
\hline 2003 & 67 & 43 & 509.5 & 183.5 & 803.5 & 77 & 298 & 358 & 875.5 & 235.5 & $3,450.5$ \\
\hline 2004 & 5 & 1.5 & 80 & 207.5 & 743 & 207.5 & 758.5 & 619 & 1,050 & 335.5 & $4,007.5$ \\
\hline 2005 & 15 & 0 & 56 & 377.5 & 1,529 & 101 & 861 & 766 & $1,258.5$ & 418.5 & $5,382.5$ \\
\hline Mean & 16.5 & 27.7 & 163.3 & 220.5 & 937.7 & 92.9 & 440.3 & 433.2 & 629.9 & 274.8 & \\
\hline SD & 17.69 & 34.49 & 153.49 & 71.99 & 343.66 & 50.56 & 213.52 & 257.47 & 286.53 & 135.08 & \\
\hline
\end{tabular}

* Caves containing swiftlets were discovered and added to the monitoring program over time; the number of caves monitored (the sample size) stabilized after 1998.

${ }^{a}$ The DCI is the sum of the annual mean of two surveys conducted in April and October, except where indicated.

${ }^{b}$ The number of caves surveyed $(n)$ was as follows: 1985, 4; 1986, 5; 1987, 5; 1988, 4; 1989, 6; 1990, 5; 1991, 4; 1992, 6; 1997, 5; 1998,$9 ; 1999,10 ; 2000,10 ; 2001,10 ; 2002,10 ; 2003,10 ; 2004,10 ; 2005,10$.

${ }^{c}$ Data are from a single monitoring period.

${ }^{d}$ Data collected in November and December. 
Doc's cave supporting the largest colony (Table 2). The remaining caves supported smaller colonies, with the two smallest (Da'ok and Celis) occasionally having no birds present at all. The sum of the yearly mean number of Mariana Swiftlets found in the monitored colonies on Saipan (Table 2) resulted in an index of population size (the direct count index) that ranged from a low of 1,040 swiflets in 1990 ( $n=6$ caves) to a high of 5,383 swiftlets in 2005 ( $n=10$ caves). Overall, numbers of Mariana Swiftlets on Saipan have increased since 1985.

We found a high degree of variability in the numbers of swiftlets inhabiting specific caves from one monitoring period to the next, sometimes on the order of hundreds of birds. For example, we recorded approximately 1,258 birds in April but only 849 individuals in October during the 2001 surveys of Doc's Cave. The high variation around the mean of biannual counts for each cave (Table 2) reflected this pattern. Analysis of count variation showed that year-to-year differences of $20-30 \%$ in individual colony counts signaled significant changes from previous levels. Arrival counts did not vary greatly from month to month (on average, less than $11 \%$ ), and we did not detect seasonal differences (April versus October) in colony attendance, unlike earlier workers who found that counts were consistently lower in the spring and summer months and higher in the fall and winter. Overall, tests of arrival counts showed they were consistent and reliable, with an estimated average difference of approximately $5.8 \%$ among observers. Arrival counts and the direct count index provided tools useful in detecting significant changes in colony size.

Both the direct count index and regression analysis of counts from four caves on Saipan

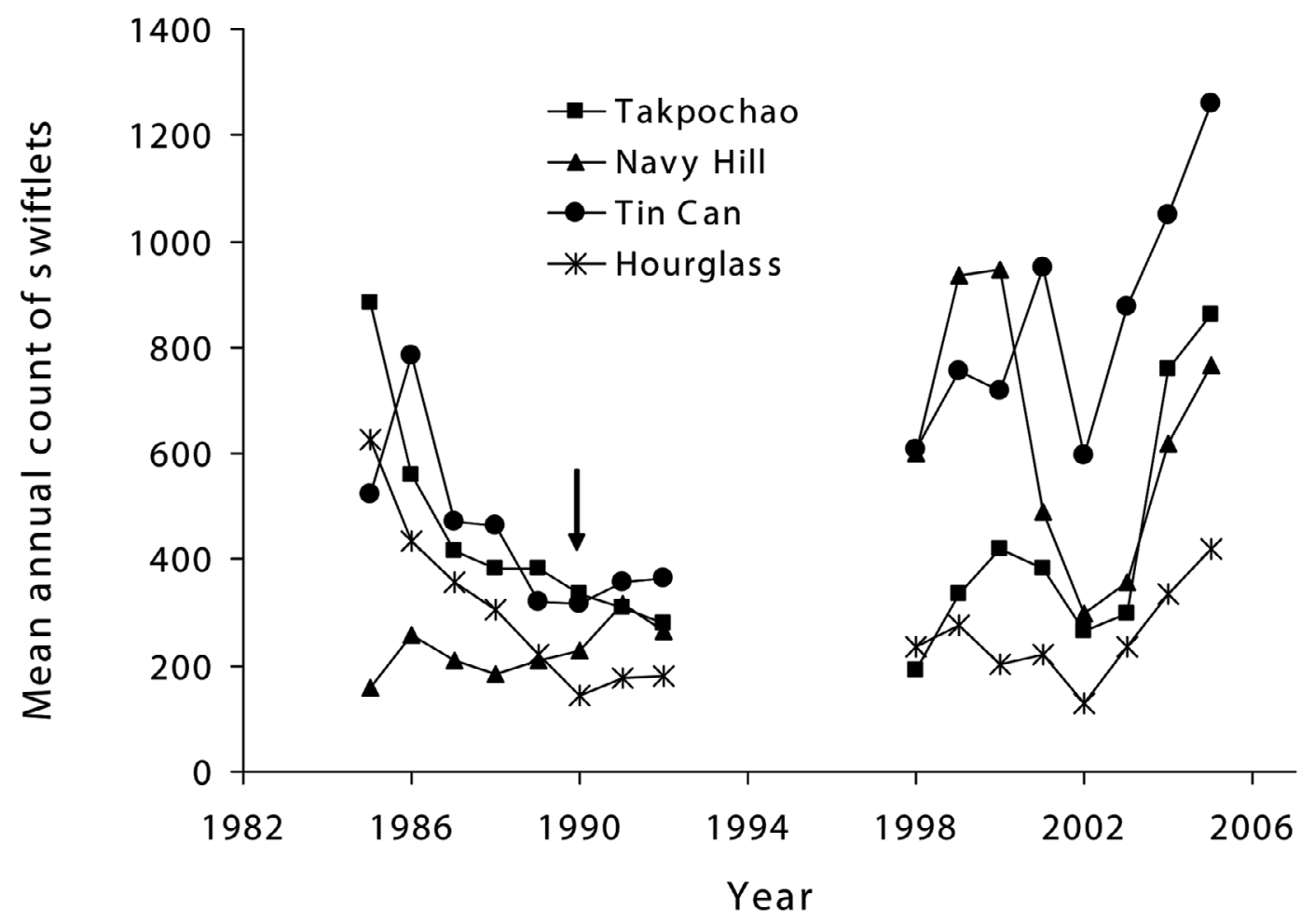

FIgURE 2. Mean annual attendance counts of Mariana Swiftlets at four swiftlet roosting and nesting caves on Saipan 1985-2005. An arrow indicates the year (1990) that cockroach control was initiated in two of the four colonies. 


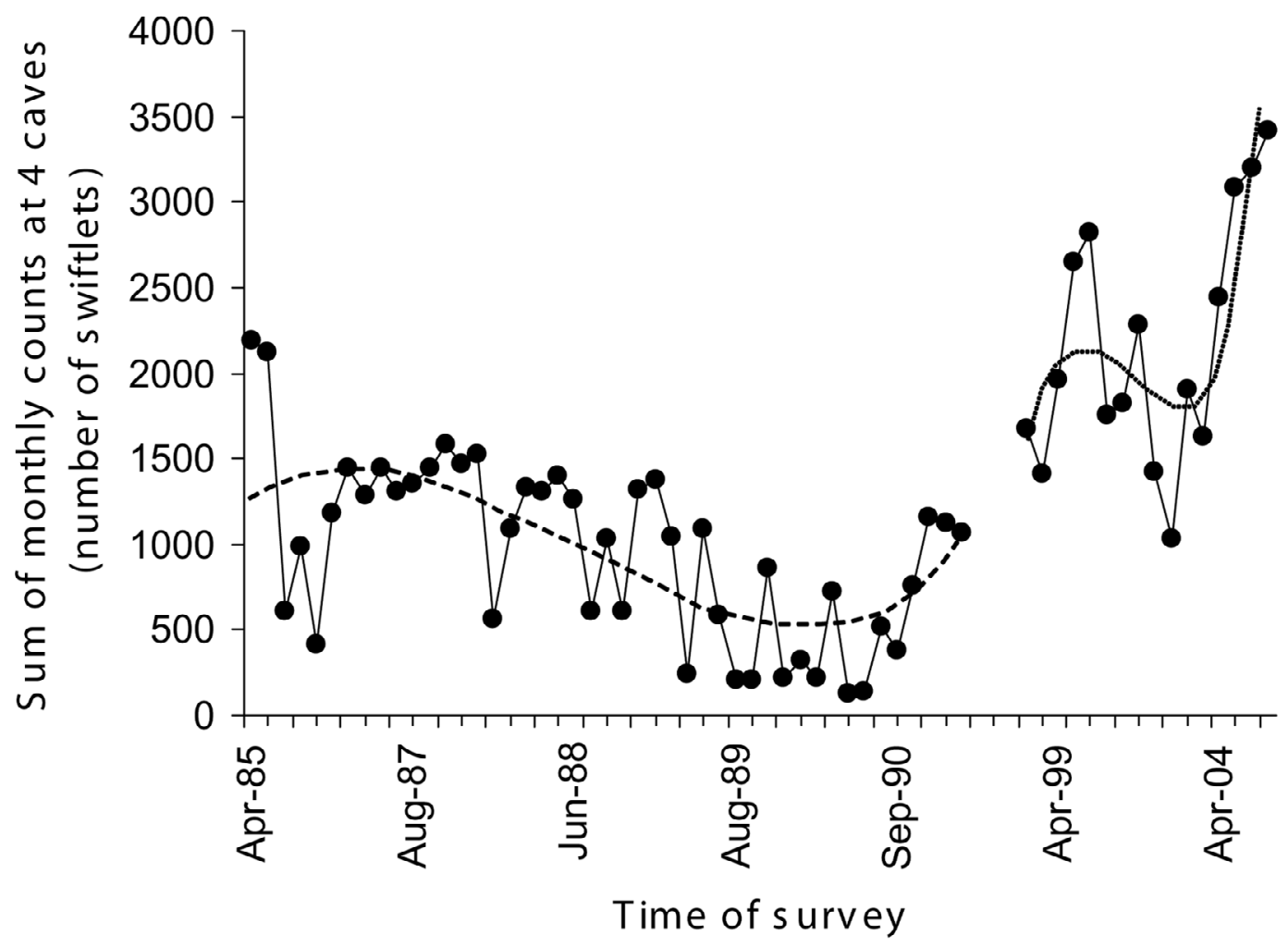

FIgURE 3. Sum of attendance counts at four major swiftlet roosting and nesting caves on Saipan 1985-2005. Data are from all available surveys (between 2 and 12 surveys per year). The dashed line represents the four-colony 1985-1992 decreasing population trend described by a second-order polynomial model $\left(R^{2}=0.43\right)$. The dotted line represents a third-order polynomial model fit to the 1998-2005 data $\left(R^{2}=0.82\right)$ describing an apparently fluctuating, but increasing, population.

indicated a decreasing trend in swiftlet numbers between 1985 and 1992 followed by higher population levels and large population fluctuations between 1998 and 2005 (Figures 2 and 3). From 1999 to 2005, when the number of surveyed caves was constant, the direct count index indicated that initially swiftlet numbers were modestly high, followed by a $31 \%$ decline between 2001 and 2002, when counts in 8 out of 10 caves dropped. But by 2003, swiftlet numbers had rebounded and continued to increase until the end of the study. Overall, the monitored swiftlet population on Saipan has increased $13 \%$ on average each year since 1999 .

Approximately $69 \%$ of the swiftlet population resided in four caves on Saipan that were monitored consistently since 1985 . Counts at all four caves ranged widely (Table 2) and were highly variable (Figure 2). Colony growth curves were not consistent among the four caves. For 1985-1992, polynomial algorithms described significant declines in the size of three colonies (Table 3) but a significant increase at one colony. Summed over the four major colonies, swiftlet numbers declined significantly from $1985(2,193 \pm 299.4$ swiftlets) to 1992 (1,095 \pm 75.5 swiftlets) (Table 3, Figure 3). For 1998-2005, colony attendance at all four caves fell and then increased (Figure 2). Increases were significant in three colonies (Table 3) and approached significance at the remaining one. Overall, the four-cave population reached 2,300 \pm 
TABLE 3

Regression Models* for Arrival Counts at Four Caves on Saipan over Two Time Periods: 1985-1992 and 1998-2005

\begin{tabular}{|c|c|c|c|c|c|}
\hline Time Period/Location & Model Fit $\left(R^{2}\right)$ & Trend & Model df & $F$ & $P<$ \\
\hline \multicolumn{6}{|l|}{ 1985-1992 } \\
\hline Takpochao & 0.72 & Decreasing & 3,27 & 23.72 & .0001 \\
\hline Navy Hill & 0.43 & Increasing & 3,32 & 7.94 & .0004 \\
\hline Tin Can & 0.42 & Decreasing & 3,26 & 6.20 & .003 \\
\hline Hourglass & 0.89 & Decreasing & 3,29 & 81.85 & .0001 \\
\hline Sum of monthly counts across four colonies & 0.47 & Decreasing & 3,41 & 12.21 & .0001 \\
\hline \multicolumn{6}{|l|}{$1998-2005$} \\
\hline Takpochao & 0.74 & Increasing & 3,11 & 10.54 & .001 \\
\hline Navy Hill & 0.42 & $\begin{array}{l}\text { ns Increasing } \\
\text { tendency }\end{array}$ & 3,12 & 2.88 & .080 \\
\hline Tin Can & 0.58 & Increasing & 3,12 & 5.50 & .013 \\
\hline Hourglass & 0.84 & Increasing & 3,11 & 19.59 & .001 \\
\hline Sum of monthly counts across four colonies & 0.66 & Increasing & 3,12 & 7.69 & .004 \\
\hline Overall trend based on monthly arrival counts $1985-2005$ & 0.55 & Increasing & 3,57 & 25.81 & .0001 \\
\hline
\end{tabular}

${ }^{*}$ Models described direction of population trend at each colony and whether or not the trend was significant ( $F$ and $P$ statistics).

326.1 birds in 1999 , dropped in 2002 to a low of $1,291 \pm 229.9$ birds ( $>30 \%$ decline), and recovered by 2005 to reach a high of $3,304 \pm$ 330.4 birds (Figure 3). The four-cave population trend for 1998-2005 was best described as fluctuating but significantly increasing.

On Aguiguan, Guano Cave generally housed the largest portion of the population, with smaller aggregations at other caves (Table 4). Of nine caves where colonies have been detected over time, between two and eight were surveyed during each field visit. Guano, Pillar, and Landing Caves were surveyed on six out of seven visits to the island (Figure 4) and often accommodated the majority of birds counted. Surveys averaged 416 $( \pm 268.8)$ swiftlets and, with the exception of 1982, the population appeared to be relatively stable. At least three caves (Stairway, New, and Black Noddy) where swiftlet colonies

TABLE 4

Arrival Counts of Mariana Swiftlets on Aguiguan, 1985-2002 ${ }^{a}$

\begin{tabular}{|c|c|c|c|c|c|c|c|}
\hline Cave & 1985 & 1987 & 1988 & 1992 & 1995 & 2000 & 2002 \\
\hline Guano & 750 & 321 & 295 & $\mathrm{~ns}^{b}$ & 123 & 337 & 183 \\
\hline Pillar & 100 (est.) $)^{c}$ & 89 & 34 & 60 & 65 & 53 & 33 \\
\hline Landing & 10 & 16 & 13 & ns & 2 & 2 & 6 \\
\hline New (\#6) & $* d$ & * & 39 & ns & 0 & $\$ e$ & 0 \\
\hline Black Noddy & 10 (est.) & ns & ns & ns & 145 & 7 & 0 \\
\hline Cliff & 100 (est.) & ns & ns & 40 & 26 & 9 & 31 \\
\hline Elvin's & * & * & * & * & * & * & 10 \\
\hline Dangkulo & * & * & $\mathrm{ns}$ & $\mathrm{ns}$ & $++f$ & $\$$ & 4 \\
\hline Stairway & * & * & * & * & ++ & $\$$ & 0 \\
\hline Total & 970 (est.) & 426 & 381 & 100 & 361 & 408 & 267 \\
\hline
\end{tabular}

${ }^{a}$ Data from unpublished Commonwealth of the Northern Mariana Island's Division of Fish and Wildlife surveys.

${ }^{b}$ ns, caves not surveyed during the visit.

$c$ (est.), bird numbers were estimated instead of counted.

$d^{*}$, caves not discovered until recent years.

$e \S$, caves where no swiftlet presence was found upon inspection so no arrival count was conducted.

$f_{++}$, caves found to contain swiftlets in 1995 by Wiles and Worthington (2002). 


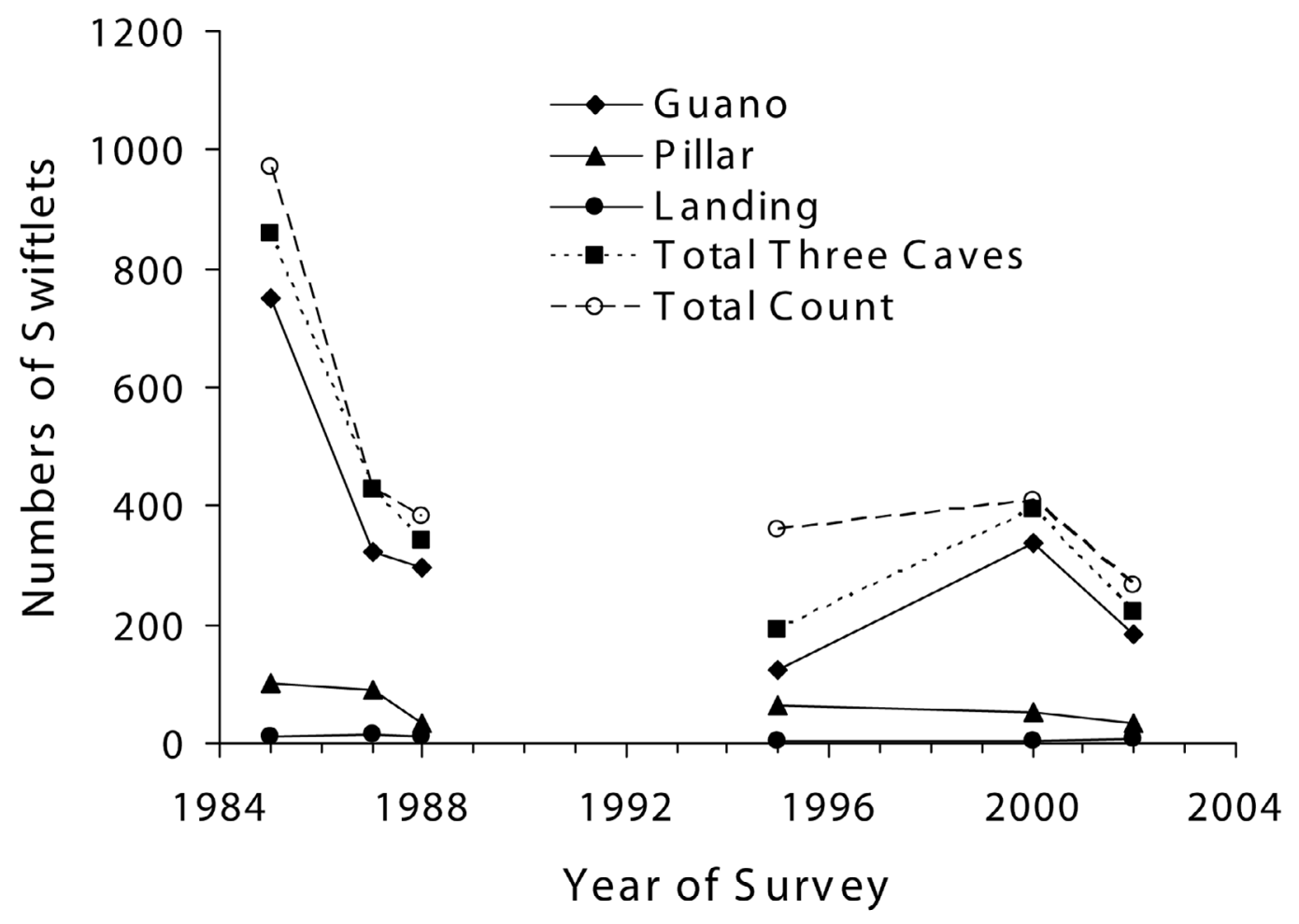

FIgURE 4. Arrival counts at three swiftlet roosting and nesting caves on Aguiguan 1985-2002. Data include counts at each cave, the total of the three caves, and the total island count for the survey period.

had been observed between 1985 and 1995 were unused in 2002.

\section{DISCUSSION}

The arrival counts resulted in a direct count index of swiftlet numbers that helped to assess relative abundance, an important tool for conservation purposes. The direct count index indicated that overall there has been a substantial increase in the Mariana Swiftlet population on Saipan since 1985. However, the 20 -yr monitoring period was marked by population decreases, increases, between-year fluctuations, and high variation in colony attendance from one survey to the next. Large population swings also have occurred in the Guam swiftlet population (Morton and Amidon 1996). The causes of the fluctuations are unknown, but we discuss cyclonic storms, pesticide use, predation, cave disturbance, in- trinsic population characteristics, and the sampling regime as potential explanations for these patterns.

Tropical storms frequently affect the entire Mariana archipelago, bringing high winds (63-118 $\mathrm{km} \mathrm{hr}^{-1}$ ) (National Oceanic and Atmospheric Administration 2005) and torrential rains that often trigger mud slides, destroy foliage, uproot trees, and damage coastal forests with salt spray. Some of these storms develop into typhoons (winds $>118$ $\mathrm{km} \mathrm{hr}^{-1}$ ) or supertyphoons (winds $>240 \mathrm{~km}$ $\mathrm{hr}^{-1}$ ) that cause extensive damage to the islands (Joint Typhoon Warning Center 2006). It is likely that the protection afforded by roosting caves ameliorates the direct impacts of such storms on the swiftlet population. However, because the species is highly localized, a relatively large percentage of the population could be lost should a cave be buried, destroyed, or flooded. In addition, 
unusually intense storms, or a series of storms, probably limit foraging opportunities in the short term and have longer-term impacts on the population through defoliation, destruction of important foraging habitat, and constraints on insect prey populations. Typhoon-related effects on swiftlet prey and foraging habitat could be particularly deleterious on Aguiguan because of its small area. Restricted to just a few caves and with a small effective population size (where the number of breeding individuals is generally less than the number of individuals counted), swiftlets on Aguiguan may be at high risk of population bottlenecks from typhoons and other stochastic events that have consequent impacts on genetic variance and genetic drift.

The main use of pesticides in the Marianas was in cultivated areas during and after World War II. Use of large quantities of organochlorine and organophosphate insecticides (especially dichloro-diphenyltrichloroethane [DDT] and malathion) for mosquito control has been implicated in the reduction of swiftlet populations on Guam and Rota (U.S. Fish and Wildlife Service 1991, Wiles et al. 2003) with likely impacts including egg-shell thinning and changes in the swiftlet's prey base. Pesticide use on Saipan has been restricted since environmental regulations have been in effect, and currently agriculture forms a minor sector of the economy. Aguiguan has been uninhabited since World War II, so pesticides are not likely to be a current negative factor on that island. The impacts of both pesticides and cyclonic storms on the swiftlet population remain concerns in need of investigation.

Predation by rats, often a cause of bird extirpations on islands (e.g., Simberloff 1995, Martin et al. 2000), probably has little effect on the Mariana Swiftlet population because rats do not seem to be able to reach swiftlet nests high on the walls or ceilings of caves. However, the feeding habits of two other nonnative species, cockroaches and tree snakes, are problematic. Cockroaches (e.g., Periplaneta americana) consume swiftlet nesting material and the gluelike saliva that secures swiftlet nests to cave ceilings or walls (C. Rice, unpubl. data). Nests attacked by cockroaches often fall, destroying the nest and its occupants in the process. As yet, the level of nestling mortality caused indirectly by swarms of cockroaches crowding birds out of the nest, or by direct attacks on swiftlet eggs, has not been documented.

Destruction of nests by nonnative cockroaches is a key mortality factor for the swiftlet population in the CNMI. A pilot cockroach control program using commercial bait traps begun in 1989 resulted in reduced cockroach numbers, less physical damage to swiftlet nests, and longer nest viability. Specifically, swiftlets reused previously constructed nests for second clutches, resulting in higher egg and nestling survival that enhanced total reproductive output (C. Rice, unpubl. data). The control program expanded to other caves in 1990, and since then cockroach baits have been replaced quarterly on Saipan and opportunistically on Aguiguan. Control of cockroach predation on swiftlet nests may have helped arrest the decline in Saipan's swiftlet population (Figures 2 and 3) and may have contributed to the recent increase in numbers.

Predation by the Brown Treesnake on Guam severely impacted 22 of the island's resident bird species including 17 of 18 native species (Savidge 1987, Wiles et al. 2003). Although pesticides may have originally reduced Guam's swiftlet population, the recovery of the species is constrained currently by Brown Treesnake predation (Wiles et al. 2003). The swiftlet continues to breed on Guam in part because birds that nest and roost high on smooth walls and ceilings are difficult for the snake to reach (Morton and Amidon 1996, Wiles et al. 2003). The southern islands of the CNMI, which receive cargo from Guam's shipping nexus, are in danger of suffering a similar pattern of avian decline and extinction should the snake infest the CNMI. The risk to the endangered Mariana Swiftlet from snake predation is extremely high now that an incipient population of Brown Treesnake is established on Saipan (McCoid et al. 1994, Colvin et al. 2005).

Human disturbance is often linked to swiftlet colony attendance patterns. On Saipan, some swiftlet caves are visited by tourists 
and relatives of people who took refuge in them during World War II, inadvertently causing birds to exit the caves for the duration of the intrusion. To reduce unintentional disturbance at those colonies, signs were posted at the entrance to three caves (Navy Hill, Hospital, and Tin Can) in 2002. Signs advise visitors of an endangered bird's presence and of its sensitivity to disturbance, asking that any memorials be left on specially constructed platforms outside the cave entrances. In addition, low rock walls were constructed to help discourage visitors or large animals from entering the cave. The effects of signs and rock barriers have been noted anecdotally in a reduction of human artifacts left inside the caves and may be another factor contributing to the recent increase in swiftlet numbers on Saipan.

Feral goats' use of caves probably causes frequent inadvertent disturbance to swiftlet colonies on Aguiguan Island. The feral goat population increased from a handful of animals in 1992 to an estimated islandwide population of 1,413 (range 943 to 2,117) in 2002 (J.B.C., unpubl. data). High ungulate density on Aguiguan has led to the general destruction of all forest types and to lack of regeneration in native forest (L.L.W., unpubl. data). The impact of habitat alteration on swiftlet food resources has not been quantified, but it may constrain the bird's population on Aguiguan.

On Aguiguan, we found several hundred swiftlets present in fewer than 10 caves. Three colonies on Aguiguan appeared to be abandoned during the study period; however, monitoring was not frequent enough to detect recolonization if it occurred between our visits, which were spaced several years apart. Although low in absolute number, the estimated population density on Aguiguan in 1995 (approximately 54.2-63.8 swiftlets $\mathrm{km}^{-2}$ ) (Wiles and Worthington 2002) was an order of magnitude greater than that on either Saipan (4.9 birds $\mathrm{km}^{-2}$ ) (this study) or Guam (0.5-1.7 birds $\mathrm{km}^{-2}$ ) (Wiles et al. 2003). Arrival counts indicated that Aguiguan's population has probably remained fairly stable at relatively high densities in recent years; however, the small size of colonies likely increases their vulnerability to local extinction from a combination of natural variation in population levels and stochastic events (Ewens et al. 1987).

Availability of nesting/roosting habitats does not appear to restrict the population on either Saipan or Aguiguan currently. Aside from the nine caves that have supported colonies on Aguiguan, seven additional caves were deemed suitable for swiftlets based on their large size and the presence of nooks and crevices in the walls and ceilings for nest support (Wiles and Worthington 2002). However, as the Brown Treesnake, a snake famous for its climbing ability, becomes established on Saipan, cave characteristics such as volume, ceiling height, and surface features assume a new importance. In the future, swiftlet persistence may depend on birds finding safe roosting and nesting niches high on cave ceilings and in areas smooth enough to limit access by the snake.

With respect to the sampling regime, the large between-year fluctuations in bird tallies on Saipan, especially the dip in 2002, did not appear to be the result of changes in monitoring personnel. We believe that the population decline between 2000 and 2002, which was consistent across eight out of 10 colonies, reflected real changes in population size. Fluctuations in colony attendance at the two smallest colonies, Celis and Da'ok, are particularly noteworthy because they were abandoned two to three times over the study period. Recolonization occurred at both caves within 12 to 18 months, suggesting that swiftlets change nesting and roosting locales with some frequency and are able to recolonize abandoned caves. Alternatively, young dispersing from nearby successful colonies may have helped reestablish Da'ok and Celis. Unlike caves that support large numbers of swiftlets, the small size of these colonies may make them more vulnerable to local extinction from normal population fluctuations (Ewens et al. 1987).

A portion of the variability in tallies from one monitoring period to the next may have been contributed by the subjective estimate initiating each arrival count. Although most swiftlets exited colonies near sundown to for- 
age, effectively zeroing the count, one source of error is the number of birds that remained undetected inside the cave. This error could be reduced by purposely flushing the birds and initiating the tally with a visual estimate of the number of nesting swiftlets remaining inside the cave. Less intrusively, employing a second survey technique, such as nighttime roost counts using infrared technology, would provide a better estimate of the error associated with arrival counts and help to confirm changes in population size. The reliability of counts might be improved by providing observers more opportunities to familiarize themselves with count protocols before conducting surveys.

In summary, the direct count index provided a minimum population estimate of $>5,300$ swiftlets on the island of Saipan but also indicated that the population had fluctuated greatly over the last $20-\mathrm{yr}$ period. Although we do not know the cause of the observed oscillations, the combined effects of nest damage by cockroaches, human intrusion into nesting caves, foraging habitat destruction by feral animals, and limits on prey populations (including the use of pesticides) may be contributing factors currently. Similar issues (e.g., human disturbance of caves for guano mining, intrusions during World War II, and heavy use of pesticides) may have contributed to the extirpation of swiftlets from Rota in the 1970s (U.S. Fish and Wildlife Service 1991, Morton and Amidon 1996). So although Saipan's population is currently at historic highs, absolute numbers are not great and swiftlet persistence is still in doubt, especially given high population fluctuations and the recent establishment of Brown Tree Snakes on the island.

\section{Conservation Recommendations}

Projects to help conserve the Mariana Swiftlet include an expansion of their distribution through translocation of birds from Saipan to other islands in the archipelago. The findings of this study may contribute to the planned translocations in two ways. First, our findings indicate that the founding cohort should be large enough to persist through naturally high oscillations in colony size. Second, the swiftlet's ability to disperse from natal colonies and nest in other caves may help establish colonies in more than one locale, augmenting reintroduction efforts. The island of Rota supported a population of swiftlets until about 1976 (U.S. Fish and Wildlife Service 1991) and may be the first target for future translocation attempts. There have been four Brown Treesnake sightings on the island since 1982 (N. Hawley, unpubl. data), so the invasive snake does not appear to have a foothold currently. The probability of achieving a reintroduction on Rota is enhanced by the swiftlet's demonstrated ability to establish a breeding colony outside its native range, as evidenced by the successful translocation of the bird to Hawai' $i$.

Conservation projects include protection of swiftlet caves from disturbance and from irresponsible visitation. Warning signs and low barriers have successfully reduced disturbance in the past; we recommend that these be maintained and the program expanded to include all known colony caves. Inadvertent disturbance of swiftlets on Aguiguan could be reduced by culling feral goats, thus benefiting the forest and potentially improving swiftlet food resources.

Protecting the swiftlet from invasive predators is critical to the continued survival of the species. Controlling the effects of cockroaches on swiftlets since 1990 may have helped boost swiftlet numbers to current highs and we recommend that this project be continued. Additional work needs to be done to keep Brown Treesnakes, one of the most devastating avian predators, at bay. Continued interdiction of the snake becomes crucial when one considers that Guam's bird populations were decimated within a few decades (e.g., Wiles et al. 2003) on an island four times larger than Saipan. At this writing, there have been 75 confirmed Brown Tree Snake detections in the CNMI (N. Hawley, unpubl. data); the risk to the endangered swiftlet is high if Brown Treesnakes invade swiftlet habitat. Identifying the remaining swiftlet caves on Saipan becomes a priority both to protect them and to conduct a baseline population survey. Continued monitor- 
ing of the swiftlet population on Saipan and Aguiguan will provide another tool to help identify areas where snakes have become established and where control should be applied.

\section{ACKNOWLEDGMENTS}

We thank in particular J. Reichel (in memoriam), R. Craig, P. Glass, C. Kessler, A. Marshall, and C. Rice whose initial work laid the basis for our comparisons. In addition we thank G. Beauprez, H. Cabrera, S. Camacho, J. Esselstyn, A. Fitial, J. Gonzales, N. Johnson, H. King, R. Lasaro, E. Masga, J. Pangelinan, A. Reyes, D. Reyes, P. Reyes, R. Ulloa, S. Rasa, J. Salas, G. Wiles, and other researchers for their field contributions. We very much appreciate the valuable comments of F. Amidon, J. Esselstyn, E. Kershner, and G. Wiles that helped to improve early manuscripts and two anonymous reviewers for their insightful appraisals.

\section{Literature Cited}

Baker, R. H. 1951. The avifauna of Micronesia: Its origin, evolution, and distribution. Univ. Kans. Publ. Mus. Nat. Hist. 3:1359.

Birdlife International. 2000. Threatened birds of the world. Lynx Ediciones and Birdlife International, Barcelona, Spain, and Cambridge, United Kingdom.

Colvin, B. A., M. Fall, L. Fitzgerald, and L. Loope. 2005. Review of Brown Treesnake problems and control programs, report of observations and recommendations. U.S. Dept. of Interior (available from http:// biology.usgs.gov/pierc/Invasive_Species/ Review_of_Brown_Treesnake_problems _and_control_review.pdf [accessed 10 December 2007]).

Commonwealth of the Northern Mariana Islands. 2000. Division of Fish and Wildlife non-commercial fishing and hunting regulations. Pages 17165-17199 in Commonwealth Register 22, 4. Saipan.

Dickinson, E. C., ed. 2003. The Howard and Moore complete checklist of the birds of the world. 3rd ed. Princeton University Press, Princeton, New Jersey.

Engbring, J., F. L. Ramsey, and V. J. Wildman. 1986. Micronesian forest bird survey, 1982: Saipan, Tinian, Agiguan, and Rota. U.S. Fish and Wildlife Service, Honolulu, Hawai'i.

Ewens, W. J., P. J. Brockwell, J. M. Gani, and S. I. Resnick. 1987. Minimum viable population size in the presence of catastrophes. Pages 59-68 in M. E. Soulé, ed. Viable populations for conservation. Cambridge University Press, Cambridge, United Kingdom.

Jenkins, J. M. 1983. The native forest birds of Guam. Ornithol. Monogr. No. 31. American Ornithologists' Union, Washington, D.C.

Jenkins, J. M., and C. F. Aguon. 1981. Status of candidate endangered bird species on Saipan, Tinian, and Rota of the Mariana Islands. Micronesica 17:184-186.

Joint Typhoon Warning Center. 2006. Naval Pacific Meteorology and Oceanography Center, Hawai'i (available from https:// metocph.nmci.navy.mil/jtwc.php [accessed 8 October 2007]).

Marshall, J. T., Jr. 1949. The endemic avifauna of Saipan, Tinian, Guam, and Palau. Condor 51:200-221.

Martin, J.-L., J.-C. Thibault, and V. Bretagnolle. 2000. Black rats, island characteristics, and colonial nesting birds in the Mediterranean: Consequences of an ancient introduction. Conserv. Biol. 14:1452-1466.

McCoid, M. J., T. H. Fritts, and E. W. Campbell. 1994. A brown tree snake (Colubridae: Boiga irregularis) sighting in Texas. Tex. J. Sci. 46:365-368.

Morton, J. M., and F. A. Amidon. 1996. Development of field techniques for studying and restoring the Vanikoro Swiftlet (Aerodramus vanikorensis bartschi) on Guam. U.S. Fish and Wildlife Service, Dededo, Guam.

National Oceanic and Atmospheric Administration. 2005. Hurricane Research Division. Atlantic Oceanographic and Meteorological Laboratory, Florida (available from http://www.aoml.noaa.gov/hrd/ tcfaq/tcfaqA.html [accessed June 2006]). 
Pauley, G. 1994. Biodiversity on oceanic islands: Its origin and extinction. Am. Zool. 34:134-144.

Pratt, H. D., P. L. Bruner, and D. G. Berrett. 1979. America's unknown avifauna: The birds of the Mariana Islands. Am. Birds 33:227-235.

- 1987. The birds of Hawaii and the tropical Pacific. Princeton University Press, Princeton, New Jersey.

Ralph, C. J., and H. F. Sakai. 1979. Forest bird and fruit bat populations and their conservation in Micronesia: Notes on a survey. 'Elepaio 40:20-26.

Savidge, J. A. 1987. Extinction of an island forest avifauna by an introduced snake. Ecology 68:660-668.

Simberloff, D. 1995. Why do introduced species appear to devastate islands more than mainland areas? Pac. Sci. 49:87-97.

Stafford, K. W. 2003. Structural controls on megaporosity in eogenetic carbonate rocks: Tinian, CNMI. M.S. thesis, Mississippi State University, Mississippi State, Mississippi.

StatSoft. 2003. Statistica. Release 6. Tulsa, Oklahoma.

Steadman, D. W. 1999. The prehistory of vertebrates, especially birds, on Tinian, Aguiguan, and Rota, Northern Mariana Islands. Micronesica 31:319-345.
U.S. Fish and Wildlife Service. 1984. Endangered and threatened wildlife and plants: Determination of endangered status for seven birds and two bats on Guam and the Northern Mariana Islands. 50 CFR Part 17. Fed. Regist. 49 (167): 33,88133,885 .

- 1991. Recovery plan for the Mariana Islands population of the Vanikoro Swiftlet, Aerodramus vanikorensis bartschi. U.S. Fish and Wildlife Service, Portland, Oregon.

Wiles, G. J., J. Bart, R. E. Beck Jr., and C. F. Aguon. 2003. Impacts of the Brown Tree Snake: Patterns of decline and species persistence in Guam's avifauna. Conserv. Biol. 17:1350-1360.

Wiles, G. J., and D. H. Woodside. 1999. History and population status of Guam Swiftlets on O'ahu, Hawai'i. 'Elepaio 59:57-61.

Wiles, G. J., and D. J. Worthington. 2002. A population assessment of Pacific Sheathtailed Bats (Emballonura semicaudata) on Aguiguan, Mariana Islands. U.S. Fish and Wildlife Service, Honolulu, Hawai'i.

Young, F. J. 1989. Soil survey of the islands of Aguijan, Rota, Saipan, and Tinian, Commonwealth of the Northern Mariana Islands. U.S. Department of Agriculture Soil Conservation Service, Washington D.C. 